\section{Musculoskeletal disorders among first-year Ghanaian students in a nursing college}

Jubilant Kwame Abledu, Eric Bekoe Offei

University of Ghana, School of Veterinary Medicine

Abstract:

Objective: To estimate the prevalence and extent of MSDs among a sample of freshmen in a nursing college in Ghana. Methods: A semi-structured self-reported questionnaire including the Nordic Musculoskeletal Questionnaire (NMQ) wa used to collect information on age, gender and musculoskeletal complaints among a random sample of 200 students at a nursing and midwifery college in the Eastern region of Ghana.

Results: Out of the 200 questionnaires administered, 160 were retrieved of which 3 were found to be incomplete and void, vielding a total of 157 evaluable questionnaires, a response rate of $78.5 \%$. One hundred and ten (70.1\%) students reported having MSDs in the previous 12 months, of which a total $88(56.1 \%)$ suffered disabling effects, while $70(44.6 \%)$ students reported having MSDs in the past 7 days. The prevalence of MSDs in the different body regions was generally low with reported having MSDs in the past 7 days. The prevalence of MSDs in the
clustered distribution in the neck, upper back, wrists/hands and lower back.

Conclusion: Nursing students are at reasonably high risk of MSDs. Strategies to prevent this important public health problem amongst future generation of nursing students must be given utmost priority. This study provides the baseline data for more elaborative studies in the Ghanaian population.

Keywords: Musculoskeletal disorders, nursing students, functional impairment.

DOI: http://dx.doi.org/10.4314/ahs.v15i2.18

Introduction
Musculoskeletal disorders (MSDs) are extremely common and affect people of all ages, gender and socio-demographic background in society ${ }^{1}$. They are a major Although MSDs represent an important health issue cause of severe long-term pain and disability ${ }^{1,2}$, pro- for college students and young adults, to date, there is ductivity $\operatorname{loss}^{3}$ and reduced quality of life $e^{4,5}$ which can a paucity of epidemiological studies in Africa ${ }^{6}$ on the lead to reduced educational attainment among students. prevalence of MSDs among this population. Available In recent years, MSDs have emerged as a public health and relevant information on MSDs in Ghana are from problem among college students, with the estimated adult populations largely of mixed age-groups ${ }^{20-25}$. prevalence rate varying between $32.9 \%$ and $89.3 \%$ in Projections made based on data from developed coundifferent parts of the world ${ }^{6-19}$. Factors such as com- tries may not accurately reflect the reality in developing puter usage ${ }^{10-13,17}$, female sex ${ }^{6,7,14,17}$, lack of regular exer- countries. The aim of this work, therefore, was to decise $^{13,18}$ and psychosocial stress and mental pressure ${ }^{6,15}$ termine the prevalence and extent of MSDs in an

apparently healthy cohort of Ghanaian young-adults at a nursing and midwifery training college in the Eastern region of Ghana.

\section{Corresponding author:}

Jubilant Kwame Abledu

University of Ghana,

School of Veterinary Medicine

Email: jkabledu@gmail.com

Thes school-based cross-sectional study involved firstyear students (180 females and 20 males) at a nursing ticipants were 18 years or older and had no history of Nordic Musculoskeletal Questionnaire (NMQ) ${ }^{26}$. Each

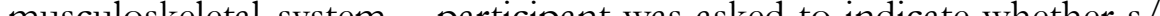
The purpose and contents of the questionnaire were explained to the subjects beforehand, and consent was obtained before participation in the study. Participation in the study was voluntary.

episode of pain or discomfort in different anatomical regions of the body (Figure 1) during the previous 7 days (point prevalence) and 12 months (period prevalence), and to indicate the severity of MSDs in the previous 12 months (i.e whether MSDs interrupted his/ Each participant was assessed by using a two-section her normal daily activities and/or required treatment self-reporting questionnaire; section one was used to or medical consultation). The questionnaires were recollect data on participants' demographic variables (i.e trieved immediately after completion on the same day. gender and age) while section two assessed participants' The NMQ has been shown to be a valid and reliable musculoskeletal complaints using the standardized instrument ${ }^{26-28}$.

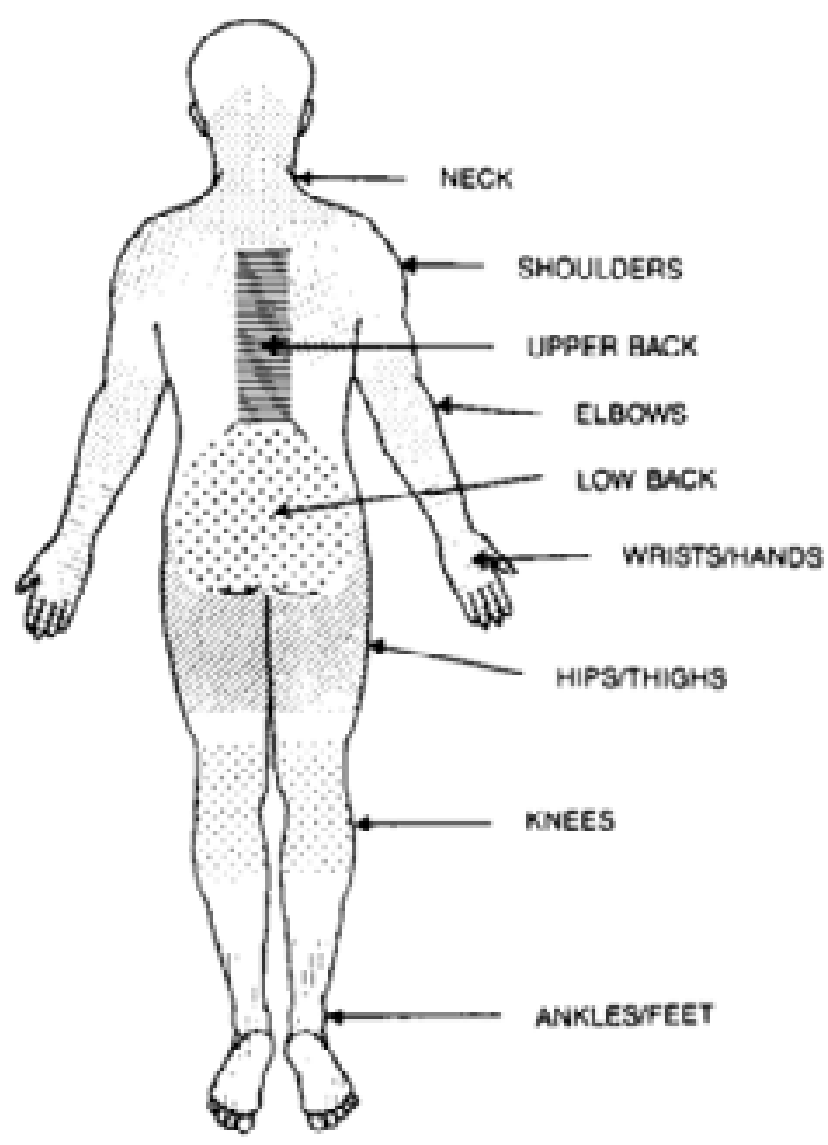

Figure 1. Regions of musculoskeletal pain/discomfort

Adapted from Kuorinka et al. ${ }^{26}$

Statistical analysis

Continuous data are presented as mean \pm standard deviation, whereas categorical data are presented as frequencies and percentages. Continuous data were compared using unpaired t-test and categorical data by Chi-square test. All analyses were performed using MedCalc for Windows, Version 12.7 (MedCalc Software bvba, www. medcalc.org $)^{29}$. In all statistical tests, a value of $\mathrm{p}<0.05$ was considered significant. and midwifery training college (name withheld for the purpose of confidentiality) in the Eastern region of Ghana, between May and June 2014. All the par-

\section{Results}

Response rate and demographic characteristics of the respondents.

Out of the 200 random questionnaires administered, 160 were retrieved of which 3 were found to be incomplete and void, yielding a total of 157 evaluable questionnaires, a response rate of $78.5 \%$. Females $(\mathrm{n}=143$ ) and males ( $\mathrm{n}=14)$ accounted for $91.1 \%$ and $8.9 \%$ of the total population respectively. The respondents' age ranged from 18-26 years with mean age being 20.9 \pm 1.8 years. The mean age of males $(20.9 \pm 1.8)$ and females $(20.9 \pm 1.8)$ were statistically comparable $(\mathrm{p}=0.7645)$. 
Prevalence of MSDs and functional impairment hips/thighs (21.0\%). Regarding the severity (i.e funcAs shown in Table 1, the point prevalence (44.6\%) tional impairment) of MSDs, 88 (56.1\%) participants among the respondents was sparsely distributed across indicated that they were prevented from carrying out most of the body regions and clustered around four their normal activities, with neck pain (23.6\%), upper MSD domains, namely wrist/hand pain (15.3\%), lower back pain (20.4\%), wrist pain (18.5\%) and lower back back pain (15.3\%), upper back pain (14.0\%) and neck pain (17.8\%) as the main contributory MSD. Overpain $(13.4 \%)$. The 12 -month prevalence was $70.1 \%$, all, there was no significant gender differences in the with a similar sparse-distribution across most body re- period prevalence $(p=0.5703)$, point prevalence $(p=$ gions, but predominant in the neck (28.0\%), upper back 0.8661$)$ and severity $(\mathrm{p}=0.5096)$ of MSDs among the (27.4\%), lower back (23.6\%), wrists/hands (22.9\%) and participants (Table 1)

Table 1 Prevalence of MSDs and functional impairment stratified by body region and gender

\begin{tabular}{lccc}
\hline & \multicolumn{2}{c}{ Total MSD complaints } & \\
\cline { 2 - 3 } & $\begin{array}{c}\text { Point prevalence } \\
(\boldsymbol{n}=\mathbf{7 0})\end{array}$ & $\begin{array}{c}\text { 12-month period } \\
\text { prevalence } \\
(\mathbf{n = 1 1 0 )}\end{array}$ & $\begin{array}{c}\text { Functional } \\
\text { impairment } \\
(\boldsymbol{n}=88)\end{array}$ \\
& $\mathbf{4 4 . 6 \%}$ & $\mathbf{7 0 . 1 \%}$ & $\mathbf{5 6 . 1 \%}$ \\
\hline Body region & & & \\
Neck & $21(13.4)$ & $44(28.0)$ & $37(23.6)$ \\
Shoulder & $9(5.7)$ & $20(12.7)$ & $16(10.2)$ \\
Elbows & $7(4.5)$ & $11(7.0)$ & $12(7.6)$ \\
Wrists/Hands & $24(15.3)$ & $36(22.9)$ & $29(18.5)$ \\
Upper Back & $22(14.0)$ & $43(27.4)$ & $32(20.4)$ \\
Lower Back & $24(15.3)$ & $37(23.6)$ & $28(17.8)$ \\
Hips/Thighs & $14(8.9)$ & $33(21.0)$ & $25(15.9)$ \\
Knees & $17(10.8)$ & $27(17.2)$ & $21(13.4)$ \\
Ankles/Feet & $9(5.7)$ & $23(14.6)$ & $15(9.6)$ \\
Gender & & & \\
Female & $64(44.8) \neq$ & $97(67.8)^{*}$ & $83(58.0) ¥$ \\
Male & $6(42.9)$ & $13(92.9)$ & $5(37.5)$ \\
\hline Datar & &
\end{tabular}

\section{Data are presented as frequencies (outside parentheses) and percentages (in} parentheses). ${ }^{*} p=0.8661,{ }^{*} p=0.5703,{ }^{\mathrm{x}} p=0.5096$ when males and females were compared using chi-square test.

\section{Discussion}

through lessons, awkward study postures and increasMusculoskeletal disorders are extremely common ing use of computers in learning. To the best of our worldwide and affect people of all ages, gender and knowledge, this is the first epidemiological study to essocio-demographic background in society ${ }^{1}$. College timate the prevalence of MSDs among a student popustudents in particular might be at high risk of develop- lation in Ghana.

ing MSDs due to habitual and prolonged sitting hours
More than half $(70.1 \%)$ of the students reported having MSDs in at least one anatomical region during the previous 12 months. This prevalence rate is in general agreement with the prevalence rates reported in the literature for college students which vary between $32.9 \%$ and $89.3 \% \%^{6-11,13-16,18,19}$. It is however higher than the $32.9 \%{ }^{8}$ and $36.9 \%{ }^{9}$ reported among nursing students in Japan, and lower than the $73.3 \%{ }^{18}$ and $80.0 \%{ }^{19}$ reported among nursing students in Korea and Australia respectively, as well as the reported prevalence among nurses at the workplace (i.e $78-84.4 \%)^{30-33}$

Despite an elevated prevalence of MSDs in this population, the prevalence of MSDs in the different body regions is lower than that reported in previous studies with similarly high prevalence rates of MSDs among college students $7,11,13-15,18,19$. Besides that, the clustering pattern of MSDs particularly in the neck $(28.0 \%)$, upper back $(27.4 \%)$, lower back $(23.6 \%)$, wrists/hand $(22.9 \%)$ and hip/thigh $(21.0 \%)$ observed from this study is somewhat different compared with findings in previou studies among nursing students ${ }^{18,19}$. Among Korean nursing students, the reported prevalence pattern was mostly in the shoulder $(46.0 \%)$, lower back $(39.1 \%)$, neck $(35.6 \%)$, feet $(25.2 \%)$ and leg $(23.8 \%)^{18}$ whereas in Australian nursing students, it was mostly in the lowe back (59.2\%), neck (34.6\%), knee (25.0\%) and shoulder $(23.8 \%)$ regions $^{19}$. The observed variations could, in part, be due to differences in population (race and ethnicity), study design and sample size, comorbidities and predisposing factors.

The observed point prevalence (44.6\%) of MSDs from this study is high and could be attributed to several factors. Worth noting is the study period- this study was conducted during the final examination period-thus, high academic stress/workload, habitual long sitting hours and poor study posture during this period might have increased the incidence of MSDs among the students. Heightened academic stress, especially during examinations, has been hypothesized as a risk factor for MSDs among undergraduates ${ }^{6}$. In their study among students in a Nigerian University, Ekpenyong et $\mathrm{al}^{6}$ found that students' stress level were higher during the examination period than the pre-examination periods, and were significantly associated with MSDs. The point prevalence of MSDs in the current study is higher than the $21.5 \%$ reported among nursing students in Japan ${ }^{8}$. It is however comparable to the estimated $46.9 \%{ }^{15}$ and $45.7 \%{ }^{16}$ prevalence rates among medical udents in China and Malaysia respectively. There is a pidemiological studies that have explored the period-prevalence, point-prevalence and functional impairment of MSDs as triadic entities in college students. However, the functional impairment rate $(56.1 \%)$ of MSDs in this study is comparable to the $41 \%$ prevalence reported in a study of upper extremity MSDs among a sample of college students ${ }^{12}$

The prevalence of MSDs would vary between sexes due to gender differences in exposure and biological and anthropometric variables ${ }^{21}$. Several studies among college students have noted a female preponderance in the prevalence of $\mathrm{MSDs}^{6,7,14,17}$. However, no sionifican sexual differences were observed in all three domains of this study (i.e point-, period-prevalence and severity). A previous study among medical students in Malaysia also found no gender differences in the prevalence of $\mathrm{MSDs}^{16}$

\section{Limitations}

This study is limited by its cross-sectional design and the use of self-reporting questionnaires, which might suffer from recall bias. Nevertheless, the results are alarming and it is hoped that this study will provide the groundwork for more elaborated and elucidative studies in the future.

\section{Conclusion}

This study suggests that Nursing students are at reasonably high risk of MSDs. Thus, strategies to preven this important public health problem amongst future generation of nursing students must be given utmost priority. Further studies are recommended to elucidate the contributory factors of MSDs among students in Ghana, as elsewhere.

\section{References}

Woolf AD, Vos T, March L: How to measure the impact of musculoskeletal conditions. Best Pract Res Clin Rheumatol 2010, 24:723-732.

2. Woolf AD, Pfleger B: Burden of major musculoskeltal conditions. Bull World Health Organ 2010, 81:646-

Martimo KP, Shiri R, Miranda H, Ketola R, Varonen H, Viikari-juntura E: Self-reported productivity loss among workers upper with extremity disorders. Scand J

Work Environ Health 2009, 35:301-308. 
4. Roux CH, Guillemin F, Boini S, Longuetaud F, Ar- 17. Schlossberg EB, Morrow S, Llosa AE, Mamary nault A, Hercberg S, Brianc S: Impact of musculoskel- E, Dietrich P, Rempel DM: Upper extremity pain and

etal disorders on quality of life: an inception cohort computer use among engineering graduate students. study. Ann Rheum Dis 2005, 64:606-612. Am J Ind Med 2004, 46:297-303.

5. Carmona L, Ballina J, Gabriel R, Laffon A: The bur- 18. Smith DR, Choe M, Chae YR, Jeong J, Jeon MY, An den of musculoskeletal diseases in the general popula- GJ: Musculoskeletal symptoms among Korean nursing tion of Spain: results from a national survey. Ann Rheum students. Contemp Nurse 2005, 19:151-60.

Dis 2001, 60(Dis 2001):1040-1045.

6. Ekpenyong CE, Daniel NE, Aribo EO: Association between academic stressors, reaction to stress, coping strategies, and musculoskeletal disorders among college students. Ethiop J Health Sci 2013, 23:98-112.

7. Smith DR, Leggat PA: Prevalence and Distribution of Musculoskeletal Pain Among Australian Medical Students. J Musculoskelet Pain 2007, 15:39-46.

19. Smith DR, Leggat PA: Musculosketet disorders 9. Smith DR, Leggat PA: Mus mong rural Australian nursing students. Aust J Rural Health 2004, 12:241-245.

20. Abledu JK, Offei EB, Abledu GK: Occupational and Personal Determinants of Musculoskeletal Disorders among Urban Taxi Drivers in Ghana. Int Sch Res Not 2014(Article ID 517259):5 pages.

21. Abledu JK, Abledu GK: Multiple Logistic Regres8. Smith DR, Omori T, Mizutani T, Yamagata Z: Hand sion Analysis of Predictors of Musculoskeletal DisorDermatitis and Musculoskeletal Disorders among Fe- ders and Disability among Bank Workers in Kumasi male Nursing Students in Japan. Yamanashi Med J 2002, Ghana. J Ergon 2012, 2:10-13.

17:63-67. 9. Smith DR, Sato M, Miyajima T, Mizutani T, Yamaga- Work-Related Musculoskeletal Disorders among Comta Z: Musculoskeletal disorders self-reported by female mercial Minibus Drivers in Accra Metropolis, Ghana. nursing students in central Japan: a complete cross-sec- Adv Epidemiol 2014(Article ID 38427):6 pages. tional survey. Int J Nurs Stud 2003, 40:725-729.

23. Quansah R: Harmful Postures and Musculoskeletal Katz JN, Symptoms Among Fish Trimmers of a Fish Processing Johnson PW, Robertson M, Dennerlein JT: Daily com- Factory in Ghana: A Preliminary Investigation. Int J Ocputer usage correlated with undergraduate students' cup Saf Ergon 2005, 11:181-190.

musculoskeletal symptoms. Am J Ind Med 2007, 50:481- 24. Bio FY, Sadhra S, Jackson C, Burge PS, Hospital BH: 488.

11. Lorusso A, Bruno S, L'Abbate N: Musculoskeletal disorders among university computer users. Med Lav 2009, 100:29-34. 12. Hupert N, Amick BC, Fossel AH, Coley CM, Rob- liminary results from a pilot study. Glob J Biol Agric Heal ertson MM, Katz JN: Upper extremity musculoskeletal Sci 2013, 2:38-41.

symptoms and functional impairment associated with 26. Kuorinka I, Jonsson B, Kilbom A, Vinterberg H, computer use among college students. Work 2004, Biering-Sørensen F, Andersson G, Jørgensen K: Stand23:85-93.

13. Hayes M, Smith D, Cockrell D: Prevalence and correlates of musculoskeletal disorders among Australian dental hygiene students. Int J Dent Hyg 2009, 7:176-181. 14. Khan SA, Chew KY: Effect of working characteristics and taught ergonomics on the prevalence of musculoskeletal disorders amongst dental students. BMC Musculoskelet Disord 2013, 14:118.

15. Smith DR, Wei N, Ishitake T, Wang R: Musculo- 29. MedCalc statistical software [http://www.medcalc. skeletal Disorders among Chinese Medical Students. org/]

Kurume Med J 2005, 52:139-146. him A, Al-ghamdi SS: Prevalence and factors associated among nursing professionals in low resource settings: a with neck, shoulder and low back pains among medical cross-sectional study in Uganda. BMC Nurs 2014, $13: 7$. students in a Malaysian Medical College. BMC Res Notes 31. Tinubu BMS, Mbada CE, Oyeyemi AL, Fabunmi 2013, 6:244.
AA: Work-Related Musculoskeletal Disorders among Nurses in Ibadan, South-west Nigeria: a cross-sectional survey. BMC Musculoskelet Disord 2010, 11:12

32. Choobineh A, Rajaeefard A, Neghab M: Association Between Perceived Demands and Musculoskeleta Disorders Among Hospital Nurses of Shiraz University of Medical Sciences: A Questionnaire Survey. Int J Occup Saf Ergon 2006, 12:409-416.

33. Chung Y, Hung C, Li S, Lee H, Wang S, Chang S: Risk of musculoskeletal disorder among Taiwanese nurses cohort: a nationwide population-based study. BMC Musculoskelet Disord 2013, 14:144. 